\title{
Qualitative evaluation of interprofessional learning initiatives in practice: application of the contact hypothesis
}

\author{
Penny J. Furness ${ }^{1}$, Helen R. Armitage ${ }^{2}$, Richard Pitt ${ }^{3}$ \\ ${ }^{1}$ Faculty of Development and Society, Sheffield Hallam University, UK \\ ${ }^{2}$ Faculty of Health and Wellbeing, Sheffield Hallam University, UK \\ ${ }^{3}$ Faculty of Medicine and Health Sciences, University of Nottingham, UK
}

Correspondence: Penny J. Furness, Faculty of Development and Society, Sheffield Hallam University, UK

Email: p.j.furness@shu.ac.uk

\begin{abstract}
Objectives: The evaluation aimed to explore reactions to, learning from and the perceived impact and sustainability of practice-based interprofessional learning initiatives established by The Trent Universities Interprofessional Learning in Practice project.

Methods: The evaluation had a qualitative design and was guided by Kirkpatrick's evaluation framework. Facilitators, managers, practitioners, students and service users were invited to participate. This article focuses upon three of the project's practice-based interprofessional initiatives. Fifteen participants were interviewed about their experiences of, and opinions about, the initiative in their practice setting. A thematic analysis was conducted, following which findings were considered through the lens of the 'contact hypothesis' a theoretical framework which sets out variables purported to influence the success of inter-group contact.

Results: Seven themes were identified. Four derived from Kirkpatrick's framework: reaction, learning, impact and sustainability. Initial reactions were positive; however
\end{abstract}

learning and impact were considered minimal, and sustainability unlikely. The evaluation revealed significant problems in developing successful, sustainable, service userfocused interprofessional learning opportunities in these three sites. Three final themes were based upon contact hypothesis variables which helped elucidate the disappointing outcomes: organisational support, positive expectations, and co-operation/working together.

Conclusions: Results offer insights which could help medical education establishments and their practice partners develop successful practice-based interprofessional learning initiatives for students in the future. Initiatives should be designed to meet local working practices and opportunities; there should be an awareness that change is challenging and time-consuming; and preparation of and support in host organisations at all levels should be a priority.

Keywords: Interprofessional learning in practice, evaluation, contact hypothesis, interviews

\section{Introduction}

Interprofessional learning (IPL) is now established in most health and social care curricula. Poor interprofessional collaboration (IPC), communication problems and misunderstandings about other practitioners' roles and pressures have contributed to significant failures in care. ${ }^{1,2}$ IPL is mandatory in pre-registration training courses in the $\mathrm{UK}^{3}$ and is highly recommended in the US, Canada, Australia., IPL occurs when 'two or more professions associated with health or social care are engaged in learning with, from and about each other' ${ }^{6}$ The aims of IPL are to reduce professional stereotyping, enhance multi-disciplinary team communication, develop collaborative health and social care teams, and improve patient care..$^{7-9}$ IPL initiatives enhance students' perception and understanding of other professions, and their ability to communicate confidently and effectively within multi-disciplinary teams (MDTs). ${ }^{10-14}$ However evaluation evidence is complicated by variations in IPL initiatives: programs may occur in academic settings 
or the clinical workplace; 'learners' could be pre-registration students and/or qualified staff; and initiatives vary in type and duration. ${ }^{12,13}$

IPL often occurs in academic settings; however practicebased activities may be considered more relevant and meaningful. ${ }^{15,16}$ Student health professionals value experiential learning through clinical IPL ${ }^{17}$ and believe that practicebased IPL helps enhance understanding and bridge the theory-practice gap. ${ }^{18}$ Formal IPL initiatives in the clinical setting were relatively rare until recently; however evidence in this area is increasing. Practice-based IPL tends occur either in specially created IP training wards or within preexisting health and social care settings, where it takes advantage of or enhances existing IP interaction opportunities.

Training wards report positive short- and long-term outcomes for students. ${ }^{10,11,19,20}$ Wilhelmsson ${ }^{20}$ found persistent gains (beyond qualification) in communication skills and IP confidence for medical students placed on the Linköping ward (Sweden) in training compared with medical students in other universities. Training wards are few so these IP placements remain a rare opportunity for health and social care students. It is arguable that making best use of existing student placements and IP encounters among qualified staff is a more accessible, cost-effective, sustainable way of achieving IPL aims. IPL projects which have been established within existing practice settings are highly varied - student participation in IP seminars whilst on placement; students modelling IP teams to solve problems; students visiting or working with service users and families. $^{16,21-24}$ Since initiatives are designed to suit local working practices and opportunities, variability is to be expected; however it creates difficulty in establishing relative effectiveness and generalisability of different initiatives, which argues the need for further evaluative research. $^{13}$

Practice-based IPL offers excellent opportunities to engage service users in educational initiatives. Although students may cooperate to care for or discuss clients, relatively few IPL projects have involved service users actively, ${ }^{25}$ despite their stake in health and social care education and willingness to participate in research aimed at improving practice. ${ }^{26}$ Results from other service userfocused health education research demonstrate greater student and staff awareness, ${ }^{27}$ service user empowerment ${ }^{28}$ and better practitioner-client partnerships. ${ }^{29}$ Trials of practice-based IPL with a service user focus are unusual. Blickem and Priyadharshini ${ }^{30}$ presented qualified staff with service user-developed narratives, improving staff awarness and service delivery; however there was no direct contact between staff and service users, and students were not included. Our evaluation of two initiatives established by Trent Universities Interprofessional Learning in Practice (TUILIP) project in which vulnerable service users were central $^{31}$ found positive outcomes were enjoyed by students, practitioners, organisations and service-users.

Understanding both what works (and doesn't) and how it works helps inform successful IPL, and Glasby and Beresford $^{32}$ suggest evaluation should consider both outcomes and processes. The 'contact hypothesis' theory ${ }^{33,34}$ suggests that simply bringing people together is insufficient to address the prejudice, stereotyping and discrimination which often occurs between groups. Allport ${ }^{33}$ and Hewstone and Brown ${ }^{34}$ proposed that certain key variables influence contact outcomes: institutional support for activities; recognition of equal status among participants; positive expectations of outcomes; a cooperative atmosphere; an understanding of role similarities and differences; participants working together as equals; and participants viewing others as typical of their group, rather than exceptional. This hypothesis has been applied to IPL initiatives ${ }^{35}$ to suggest that carefully managed contact between different professional groups can improve attitudes, tackle negative stereotyping and prejudice, and strengthen collaborative teams. ${ }^{36}$ Hean and Dickinson ${ }^{37}$ and others ${ }^{35}$ report that IPL initiatives based upon the contact hypothesis have been successful in altering learners' attitudes and stereotypes.

\section{The TUILIP project}

The TUILIP project was launched in 2005 to address the combined needs for further evaluative work, a focus upon IPL in practice and greater service user involvement. TUILIP aimed to develop service-user focused sustainable models of IPL that would promote and facilitate students' professional skills through collaborative working within practice settings. Through the project, leads also aimed to enhance and extend classroom-based IPL already offered to students at the two collaborating Universities (Sheffield Hallam University and University of Nottingham). ${ }^{38}$ Over four years, eight pilot sites were developed in NHS trusts/ private and voluntary sector across the Trent region, involving students and practitioners from 13 health and social care professions. A broad range of primary and acute health and social care settings were included. The project team and trusts collaborated to identify settings, criteria for selection including existence of an IP team, naturally occurring opportunities for collaborative working, and regular placement of student health and social care professionals. Practitioners in each setting were prepared for TUILIP through information and discussion meetings run by project leads.

Interprofessional learning facilitators were recruited to the TUILIP project part-time for up to twelve months. Some facilitators were already employed within the setting and seconded for 2-3 days per week into the TUILIP project; others were external recruits. Some were lone facilitators; others were employed on a job-share basis. Facilitators in the 3 settings which form the focus of this article were externally recruited and worked alone. 
Facilitators were selected on the basis of experience (clinical, educational and managerial) and enthusiasm for IPL, and individual preparation for the role was based upon a learning needs analysis. ${ }^{38}$ Facilitators accessed universitybased educational resources and participated in classroombased IPL before venturing out into their particular practice environment. They were made aware of the TUILIP project's general aims but not given a specific remit beyond this. Facilitators were therefore expected to research and identify opportunities for IPL within their pilot area. Through collaboration with managers, practitioners (and, ideally, service user groups), they were supported to promote change and provide innovative learning opportunities which were both sustainable and relevant to the setting, the clients, students and practitioners. Following each pilot, a qualitative evaluation was conducted. The evaluation aimed to gather from participant stakeholders their perspectives on the TUILIP initiatives in their setting, including:

- their reactions to and experiences of the initiatives

- their views regarding its impact upon student / practitioner learning and behaviour

- their perception its long-term impact and sustainability

\section{Methods}

\section{Design}

This was a qualitative evaluation, designed to gather the reactions and perceptions of all relevant stakeholders. The evaluation was based upon Kirkpatrick's evaluation framework. ${ }^{39}$

\section{Setting}

This article reports findings from 3 of the 8 TUILIP pilot sites: a medical admissions unit (P1), community-based women's services (P2) and a pair of GP surgeries (one townbased; one rural) (P3). NHS ethical approval was obtained (North Trent NHS Research Ethics Committee, UK) and permissions granted by local research and development departments.

\section{Sample}

PF (research fellow) identified people who had been involved with TUILIP initiatives in each site through discussion with site facilitators and project leads (HA; RP). Twelve were identified from P1 (1 facilitator; 1 manager; 8 practitioners; 2 students); 5 from P2 (1 facilitator; 2 clinical managers; 2 practitioners; no service users or students were nominated as potential participants); and 11 from P3 (1 facilitator; 2 lead GPs; 8 practitioners; no students or service users). The lack of student and service user involvement was reflective of difficulties encountered in engaging these groups in initiatives. We contacted potential participants by email or letter, provided them with information about the evaluation, and invited them to participate in either inter- views or focus groups at a mutually convenient time and location.

From a possible sample of 28,15 participants responded to our invitations (8 from P1, 3 from P2, 4 from P3); participants included 3 facilitators, 5 managers, 6 practitioners and 1 student. Despite small numbers, professions represented within the sample included medicine, nursing, occupational therapy, radiography and physiotherapy. Given low student engagement in the evaluation, we included qualitative comments from feedback questionnaires ( $\mathrm{n}=$ 15) gathered by $P 1$ facilitator, which reported perceived learning from students/practitioners attending IP lectures organised in that site.

\section{Data collection}

In these 3 sites, stakeholder numbers were too low to support the use of focus groups, so PF interviewed all participants individually. Data collection was guided by Kirkpatrick's evaluation framework, ${ }^{39}$ focusing upon participant reactions, and their perceptions of learning, behaviour change and sustainable impact. Kirkpatrick's 4-level model was developed to assess the effectiveness of training but has since been used in the fields of business, school education and to evaluate IPL programs. ${ }^{40}$

Interview questions included 'what are your thoughts about the TUILIP initiatives you have taken part/been involved in?' (reaction), 'what do you feel you learned from taking part / being involved in the initiatives?' (learning), 'what changes have occurred as a result of the initiative?' (change), 'do you believe it will be possible to sustain this initiative in this setting when the facilitator leaves/after the pilot phase?' (sustainability).

Interviews were digitally recorded with participants' permission, transcribed, anonymised, and loaded into NVivo, a software package designed to assist in the storage, coding and retrieval of qualitative data. PF conducted and transcribed all interviews, and carried out a thematic analysis $^{41}$ of all transcripts. Analysis involved line-by-line coding of each transcript and, through constant comparative analysis, development of data categories and themes. Overarching themes were determined by Kirkpatrick's evaluation framework; however within each of Kirkpatrick 4 levels the rich data and inductive analysis process yielded a range of subcategories. During the analysis process, PF presented emerging themes in meetings with project leads (HA; RP) and the steering group. Sometimes discussions involved the sharing of perspectives upon the pilots. Although project lead and steering group perspectives enabled PF to achieve a broader contextual understanding of participant responses, she was mindful of the need for independence, to avoid allowing project management views to bias the analysis, and to ensure resulting reports reflected participant perspectives. We generated summaries and formal reports of the evaluation, which were provided to all sites and participants. We have reported the process and 
outcomes of the first pilot site and evaluation results from two highly successful service-user focused pilots elsewhere..$^{31,42}$

\section{Results}

Four themes were identified based upon Kirkpatrick's evaluation framework: Reaction, Learning, Impact and Sustainability. Themes are summarised below and in Table 1 , which provides an overview of the findings according to Kirkpatrick's framework. Three further themes are presented, based upon contact hypothesis variables ${ }^{33,34,43}$ which appeared influential upon the difficulties and disappointing outcomes in these three sites: Institutional support for the learning activities, Positive expectations regarding outcomes of the activities and Co-operation/working together.

\section{Reaction}

As indicated in Table 1, participants were sympathetic to the aims of IPL and TUILIP; however positive initial reactions were replaced by disappointment when the project's full potential was not achieved:

"I think the concept is good and worth pursuing however I don't
think it ever got off the ground." (practitioner, P1)

"Overall our team were very disappointed and feel that an excellent opportunity has been missed." (manager 2, P3)

\section{Learning}

In each site, learning materials were developed (such as information leaflets with an IPL focus in P1) and activities were arranged (such as open-access lectures in P1; educational workshops and discussion sessions for staff in P2 and P3). Attempts to engage a range of professionals were not very successful, resulting in uni-professional attendance or a profession - specific focus which did not meet IP learning needs, and little cross-professional contact occurred. Although facilitators met students individually and discussed IPL, student engagement - as well as service user involvement - in group activities was rare:

\section{"Student involvement came right at the end of the project with insufficient time given to be able to organise things". (practi- tioner, $\mathrm{P} 1)$}

In P1, a number of students attended the IP lectures delivered by a single professional to a multi-professional audience. Feedback included positive comments from students (especially those of the same profession as the presenter): "whole session very helpful", "a very good presentation which makes a topic I find difficult to understand and remember, easier to grasp". Students from other professions had learned less: "Not really relevant to [my student group] as it was a little in-depth, more suitable for [other professions]"; "Some of the terminology was over my head as this isn't something I've studied before".

Although some learning took place, therefore, it was not quite as anticipated by the project. There was no evidence of student IPL as defined above ('learning with, from and about each other ${ }^{6}$ ) or as intended by TUILIP. Facilitators gained IP insights to take back into their own practice, however, and as demonstrated in Table 1, some participants felt staff and organisational IPL awareness had been raised.

\section{Impact}

Beyond raising awareness of IPL, most believed that TUILIP had no impact upon their setting, as indicated in Table 1. Some felt the main outcome was increased understanding of the difficulties of setting up IPL and changing practice:

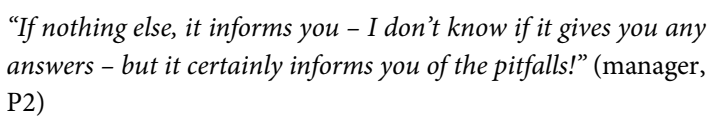

\section{Sustainability}

Few participants believed materials and activities were sustainable beyond the pilot period through lack of a champion; however Table 1 shows that, in one site, one individual was keen to develop what the facilitator had begun, creating some optimism about longer term potential for TUILIP.

\section{Institutional support for the learning activities}

Hewstone and Brown ${ }^{34}$ cite institutional support as a key facilitator of successful intergroup contact. Support was essential in determining the success of other TUILIP sites. ${ }^{31}$ Shortfalls in support for the project and its facilitators in these 3 settings were significant in limiting their success.

\section{Financial support}

Facilitators were funded by TUILIP but no additional funding was available to promote practitioner involvement. This limited staff support, sometimes through a perception that the initiative wasn't valued by the organisation:

\footnotetext{
"We got a huge response to the initial steering group meeting this Conservatory was full! So people were interested, but obviously as time goes by, numbers depleted as workload encroached and it became clear as well that there was no money backing this initiative up". (practitioner, P1)
}

Financial 'priority-setting' (manager, P2) prevented staff being released from clinical duties to support initiatives. Funding changes within some organisations exacerbated financial uncertainty and prevented financial commitment to the project:

\footnotetext{
"[the GP team] were told there was no more money for integrated nursing, so if they wanted to do it, it was up to them ... they felt it was a lot of time out, two hours a month, to meet, and some people were saying, 'it's too expensive, we can't release you for that'. So although I'd set up all the timings and all the dates, venues, they decided that the time wasn't right and they weren't going to participate in those. So that fizzled out". (facilitator, P3)
} 
Table 1. Results of evaluation, based upon Kirkpatrick's 4-level framework

\begin{tabular}{|c|c|c|c|}
\hline Kirkpatrick's levels & Themes & Categories & Codes \\
\hline \multirow{9}{*}{ Reaction } & \multirow{3}{*}{$\begin{array}{l}\text { Responses to TUILIP } \\
\text { and its initiatives }\end{array}$} & Initial impressions & $\begin{array}{l}\text { Timely; important; useful for our team; hoping for new insights; scepticism } \\
\text { replaced by enthusiasm }\end{array}$ \\
\hline & & Re. specific activities & $\begin{array}{l}\text { Helpful; enjoyed it; had some relevance to me } \\
\text { Didn't meet my needs; not sure how useful it was; disappointing attend- } \\
\text { ance; didn't meet aims }\end{array}$ \\
\hline & & Final thoughts & Disappointing; opportunity missed; still worthwhile \\
\hline & \multirow{2}{*}{$\begin{array}{l}\text { Perceptions of the } \\
\text { facilitator/role }\end{array}$} & Facilitator & Tried hard; struggled to contact people/make progress \\
\hline & & The role / task & Challenging task; glad it wasn't my role; nightmare job \\
\hline & \multirow{2}{*}{$\begin{array}{l}\text { Support and } \\
\text { acceptance within } \\
\text { the organisation }\end{array}$} & Management & $\begin{array}{l}\text { Not top trust priority; senior managers keen; line managers had other } \\
\text { priorities }\end{array}$ \\
\hline & & Practitioners & $\begin{array}{l}\text { Involvement variable; couldn't see benefit; didn't want anything extra to } \\
\text { do; enthusiasm waned - task seemed too difficult; didn't inspire me; will it } \\
\text { be over soon? }\end{array}$ \\
\hline & \multirow[b]{2}{*}{$\begin{array}{l}\text { Perceived drivers and } \\
\text { barriers to progress }\end{array}$} & Drivers & (none identified) \\
\hline & & Barriers & $\begin{array}{l}\text { Lack of clarity in project aims and focus; lack of local knowledge and } \\
\text { understanding; employment of 'outsider' to facilitate; time limitations; } \\
\text { clinical priorities; logistical issues and red tape, change (in service/team } \\
\text { members); challenging setting (esp. community) }\end{array}$ \\
\hline \multirow{6}{*}{ Learning } & \multirow{2}{*}{ Student } & None & Students not involved in IP activities \\
\hline & & Medical & Factual learning through IP-hosted lectures \\
\hline & \multirow{2}{*}{ Staff } & Awareness & Raised awareness of IPL issues and opportunities, IPL 'seeds planted' \\
\hline & & Medical & Factual learning through IP-hosted lectures \\
\hline & Organisation & Awareness & $\begin{array}{l}\text { Challenges of practice-based IPL; insights into how team respond to } \\
\text { initiatives }\end{array}$ \\
\hline & Facilitator & Awareness & New insights for own practice \\
\hline \multirow[t]{2}{*}{ Impact } & \multirow[t]{2}{*}{ Upon organisation } & Minimal & $\begin{array}{l}\text { We've not changed our practice in any way; long-term impact on setting } \\
\text { doubtful }\end{array}$ \\
\hline & & Negative & May have made us more wary \\
\hline \multirow{2}{*}{ Sustainability } & \multirow{2}{*}{ Of initiatives } & Unlikely & Hard to sustain; nobody is pushing it \\
\hline & & Depends on & Needs 'champion' to take ideas forward; someone here might take that on \\
\hline
\end{tabular}

\section{Support at all levels of organisation}

Agreement for piloting TUILIP was achieved through initial consultation with senior managers; therefore support at this level was established at the outset:

"The GP in charge of the project was very enthusiastic, he was full of ideas and enthusiasm to start with." (facilitator, P3)

Despite preparatory work, enthusiasm among other practitioners was lacking. Some of the facilitator's key roles - to generate, utilise and maintain the support of practitioners were very difficult to achieve. Facilitator, P3, commented, "people were very sceptical as to who I was", and manager 1 (P3) observed:

"It was thought that once engagement had occurred, we'd go onto stage $B$ and stage C. It wasn't recognised how important stage A was. And I think that would be quite an important learning thing, on how to engage your audience, because if you haven't got your audience engaged, then anything else you do, doesn't work".

In P3, the enthusiasm of the lead GP was not shared by his colleagues or the wider MDT. In P1 and 2, senior manage- ment support was not mirrored among middle managers, who were satisfied with existing practice and training, doubtful of the usefulness of TUILIP, and reluctant to respond to facilitator approaches. This slowed progress, and meant that ward staff weren't often released to attend and that their interest and engagement with the project was discouraged:

"I think some of it is leading by example, really, because none of the ward sisters came to the workshops. I know they needed staff to cover the ward to release staff, and I am aware of that, but there wasn't much interest shown to the staff about the project, really, and that was quite hard to encourage. But actually when you were in the sessions with the staff, they were very well received, despite the fact that they were giving up some of their time". (facilitator, P2)

Some suggested that managers needed to take a more proactive approach: support might have been increased by " $a$ bit of power from above to put pressure on people who were reluctant to get involved" (practitioner, $\mathrm{P} 1$ ).

"I think if you buy in at a higher level, and it's driven at that level, then it has a greater chance of success" (practitioner, P2). 
Unfortunately, managers did not encourage practitioners, and a lack of staff interest also rubbed off on students:

"The district nurses had students continually for the time I was there and I asked each time, could they get in touch with me so I could meet them, and I was never contacted by any of the students. They had some registrar medical students that I spoke to, and their feeling was that they were already doing interprofessional learning". (facilitator, P3)

Results suggested, therefore, that support - or a lack of it trickled down through the organisation from managers to staff to students. Stronger efforts in initial project stages to maximise middle management engagement and encourage senior managers to promote the project may have reduced support shortfalls.

\section{Factors which impaired support for TUILIP}

In addition to variations in management engagement and a lack of financial support, other issues which limited enthusiasm for TUILIP included the employment of 'outsiders' to facilitate, vagueness in the remit, workload and time constraints.

Facilitators in these sites were external to the organisations, in contrast to some other TUILIP sites. ${ }^{31}$ Arriving as a newcomer with a change remit was considered extremely challenging due to the extended, time-consuming orientation and familiarisation process, a lack of local knowledge which limited understanding of what would be acceptable and feasible, and natural (but discouraging) scepticism from existing staff. TUILIP's remit was deliberately broad to encourage development of locally appropriate initiatives; however this made it difficult for facilitators to understand and explain what TUILIP meant for their setting, and choose a clear focus. One GP stated:

\footnotetext{
"I felt the project was rather woolly in its objectives. Personally I didn't really know it was going to happen or why it was happening or what we were supposed to achieve by it" (P3).

"An inability to clearly translate the aims of the project and predict its impact meant facilitators struggled to engage staff who have limited time and 'work within very tight guidelines, schedules, targets [in a] very target-driven NHS" (practitioner, P1).
}

A lack of time, high workload and the clinical imperative that "patient care activity comes first" (various participants, P1) naturally impacted upon practitioner support, especially for a project which wasn't fully understood and whose sustainability was uncertain. One participant noted that support issues for IPL were ongoing and would have taxed anyone taking on the TUILIP task:

"if it was easy we'd have had this in place 3 or 4 years ago, because that's how long we've been chipping away at things" (manager, P1).
Facilitators' efforts to scope practitioner ideas and engage them in the project resulted in expectations that staff would spend time developing initiatives alongside the facilitator. One practitioner $(\mathrm{P} 1)$ remarked:

"The project in general seemed to rely too heavily on time commitment from professionals who are already stretched and who work shifts".

There was little guidance about the division of labour between facilitator and staff in TUILIP-related work; however the most successful facilitators were those who expected less from practitioners and took a consultative but self-directed approach to the development of initiatives. ${ }^{31}$

\section{Positive expectations regarding outcomes of the activities}

Hewstone and Brown ${ }^{34}$ state that positive expectations will enhance participant engagement in and learning from group activities. In IPL, this typically refers to students of different professions undertaking activities together; however here, positive expectations were also required at an organisational level. Analysis suggested that staff and manager expectations of TUILIP impacted upon its outcomes, in particular that low expectations may have limited the enthusiasm, time and support for TUILIP and its facilitators.

IPL was considered important; however the prospect of an IPL initiative in their area in the form of the TUILIP project met with varied expectations, including both hopeful anticipation and scepticism:

\footnotetext{
"I know it was another initiative, initiative in inverted commas, that seemed to appear with an acronym, and your first thought is, oh crikey, what now, you know? There've been a number of things which have come and gone over the years... and I was just concerned that I was being asked to be involved in something else, which was just going to come and go and not bear fruit." (practitioner, P1)
}

Some practitioners thought TUILIP "a lovely idea in theory" but doubted its likely success (facilitator, P3). Although some had high hopes and had emerged "disappointed" (various, P1), many of these participants began with low expectations and were unsurprised when the project did not fulfil its aims. The notion of the self-fulfilling prophecy ${ }^{44}$ is arguably relevant: low expectations limited interest and engagement, which reduced success and apparently confirmed participants' low expectations.

\section{Cooperation/working together}

Hewstone and Brown ${ }^{34}$ identify 'a cooperative atmosphere' and 'participants working together as equals' as important to successful inter-group contact. In some sites, the 'cooperative atmosphere' required for successful contact was damaged by low expectations and poor engagement among 
some practitioners. However, a more basic problem was a lack of opportunity for different students or qualified health professionals to meet and undertake joint activities. In community-based P2 and P3, occasions and opportunities for meetings were rare. Facilitators found it difficult to contact and bring relevant practitioners together, even when these efforts had management support. In retrospect, the community was considered a complex and difficult setting for the TUILIP remit because practitioners are "all scattered and working independently" (manager, P2) or "in their clinics ... behind closed doors" (facilitator, P3).

Practitioners tended to operate uni-professionally, met relatively rarely and multi-disciplinary meetings were precious, purposeful, had a full clinically-focused agenda, with little scope to introduce IPL-related activities. Nonetheless, practitioners did not want community-based IPL endeavours to be abandoned simply because they were challenging:

"I wouldn't want people to say it's too hard to do in general
practice, so let's stop doing it." (manager 1, P3)

They believed that the community was a crucial setting for IPL, given that care is increasingly community-based and practitioners tend to work separately. Instead, they felt that, in designing initiatives, researchers should be aware that "the community is just huge and broad and works very differently" (manager, P2). They felt that the project team had not grasped how things worked, and suggested that future projects be designed specifically for the community, with careful consideration of existing patterns of working, practicalities and limitations.

\section{Discussion}

This article has reported outcomes and influential process aspects in three TUILIP project pilot sites where attempts to create IPL initiatives encountered significant difficulties. Despite facilitator efforts, student learning, service user involvement, behaviour change and impact outcomes were very limited.

Hean and Dickinson ${ }^{37}$ note that theoretical frameworks can help inform researchers, academics and clinicians in developing and evaluating IPL interventions. In this study, Kirkpatrick's framework ${ }^{39}$ helped identify the limited extent to which anticipated outcomes - learning, behaviour change and sustainable impact - occurred. Although not part of the original design, the 'contact hypothesis' ${ }^{33,34,43}$ proved valuable in analysing factors which limited achievements, as it has elsewhere: Barnes, Carpenter and Dickinson ${ }^{45}$ found that missing contact hypothesis variables helped explain why their IPL intervention within a community mental health team did not produce expected attitude changes. The contact hypothesis has previously been applied to IPL activities with learners; however since little development work found its way to students in these TUILIP sites, these results indicate that certain contact hypothesis variables can also help inform, analyse and evaluate IPL success (or otherwise) at a higher, organisational level. Patchy institutional support for activities; less than positive expectations of outcomes; and difficulties enabling participants to work together slowed progress and restricted outcomes.

\section{Support, expectations and cooperation}

In these 3 sites, hearts and minds had clearly not been won over by TUILIP, and lack of time, progress or focus sapped initial enthusiasm and involvement. Medical staff seemed particularly difficult to engage, including in P3, where medical professionals were predominant. Reeves and colleagues $^{46}$ suggest that exclusive status of the medical profession reduces their perceived need to engage in IPL. The status issue did not emerge from this evaluation with the few participants; however the facilitator and lead GPs clearly perceived reluctance among medical staff, which may have reflected disinterest in IPL, scepticism about TUILIP, or simply lack of time. Support in practice-based IPL is less well researched than University-based projects, which report resource shortfalls, high demands upon staff and concerns about workload. ${ }^{7,47}$ Rees and Johnson ${ }^{48}$ reported scepticism and resistance to academic IPL initiatives, and these factors were evident here too. Rice et al. ${ }^{49}$ attempted to establish a brief practice-based IP intervention to improve IPC and communication; similarly they found that changes in staff support for the project, other priorities, an interruptive environment, and a perceived lack of benefits reduced engagement with and anticipated outcomes from the project. They argue, as suggested above, that commitment and support at all levels of the organisation are required to bring about even small changes in IP practice.

Furness et al. ${ }^{31}$ found that TUILIP sites least troubled by support issues were facilitated by familiar, respected figures within the organisation, with influence over practitioner attendance and strong local knowledge. Facilitators did not rely heavily upon staff in developing ideas or running initiatives, which maintained their goodwill and support, and remained in post to maintain initiatives after the pilot. In contrast, these three sites were facilitated by an experienced 'outsider', with limited knowledge of environment or staff. The evaluation suggested these facilitators struggled to overcome scepticism, earn credibility, and identify clearly focused, workable ideas within the limited time for their pilot.

\section{The community setting}

Certain settings chosen for TUILIP pilots were not, in retrospect, ideal for the project. The evaluation suggested that difficulties in the community context (P2 and P3) included funding issues, geography and independent working. There is little comparable evidence in IPL literature, but researchers have highlighted the complexities and challenges of community healthcare research..$^{50,51}$ Similarly 
to practitioners here, Harrison ${ }^{51}$ urges researchers to address specific primary care objectives, and managers of community services to do more to strengthen the organisational support, opportunities and structures for research. Existing community practitioners who understand working practices and limitations, and enjoy local contacts and support, may have greater success in developing IPL initiatives in this challenging setting.

\section{Implications}

IPL has great potential in the education of medical and healthcare professionals, but is challenging to establish, deliver and maintain. ${ }^{52}$ The TUILIP project has enjoyed varying levels of success, and evaluation of different sites, including the three reported here, has highlighted key lessons regarding IPL in practice.

Settings for IPL initiatives should be selected pragmatically based upon potential costs, barriers and benefits, with consideration given to local working practices. Managers and practitioners should be involved to maximise understanding of and support for initiatives at all levels of the organisation. ${ }^{47,53}$ Practitioner involvement in design and delivery of initiatives may encourage their enthusiasm and engagement but time limitations and clinical priorities should be considered. A committed organisation should facilitate staff involvement and attendance and ensure the initiative is considered important at all levels. ${ }^{49}$ Sustainability is a priority, so careful consideration should be made regarding long-term embedding, maintenance and resourcing.

Facilitators should ideally be employed from within the organisation or allowed extra time for familiarisation and offered supportive links with key individuals within the organisation. Providing information (or encouraging research) about previous successful and unsuccessful initiatives in similar settings may facilitate effective planning and implementation. To achieve their challenging agenda, IPL facilitators should have sufficient time to thoroughly research, plan, implement, evaluate and embed the initiative, as well as enthusiasm for IPL, creativity, motivation, project completion and communication skills.

\section{Limitations}

Non-responder perceptions of TUILIP may have differed. People with positive perceptions of a project may be more likely to respond to invitations, potentially creating a favourable bias in the results: it may be that nonrespondents' views were even less positive. However, practitioners and facilitators were very frank with their opinions, and we have tried to present a balanced view.

The research fellow $(\mathrm{PF})$ responsible for data collection and analysis was independent of the TUILIP management and steering teams. Steps were taken to maximise objectivity: interview recordings were transcribed verbatim and participants, offered interview transcripts and the opportunity to identify errors. As with any research study, bias 90 may have been introduced in the way that questions were asked, responses followed up, data analysed and selected for presentation, based upon PF's background as a health professional, academic and researcher, her personal interest in interprofessional learning, and her relationship with the project team. She made efforts, however, to represent all views fairly and to avoid bias.

\section{Conclusion}

Introducing practice-based IPL initiatives is challenging for higher education institutions training medical and healthcare professionals and their practice placement partners. Three contact hypothesis variables helped explain the disappointing outcomes in these three TUILIP pilots: organisational support, positive expectations, and cooperation/working together. To overcome barriers and maximise success, educators and practitioners should collaborate to ensure interventions are clearly articulated and designed to meet the needs, IP opportunities and current working practices of students and practitioners in the setting. Support at all levels of the host organisation is essential, and those employed to develop and deliver interventions should be well-resourced in terms of time, preparation and support.

\section{Acknowledgements}

The authors would like to acknowledge the hard work and dedication of the facilitators in the TUILIP pilots reported here and the contributions of all participants to the evaluation process. The authors also wish to thank Professor Frances Gordon, Sheffield Hallam University, for reading and offering suggestions about earlier versions of this article.

\section{Conflict of Interest}

The authors declare that they have no conflict of interest.

\section{References}

1. Atwal A. A world apart: how occupational therapists, nurses and care managers perceive each other in acute care. British Journal of Occupational Therapy. 2002;65:446-52.

2. Bristol Royal Infirmary Inquiry. Learning from Bristol: the report of the public inquiry into children's heart surgery at the Bristol Royal Infirmary 1984-1995. Bristol: Bristol Royal Infirmary; 2001.

3. Department of Health and Quality Assurance Agency. Department of health phase 2 benchmarking project - final report. London: Department of Health \& Quality Assurance Agency for Higher Education; 2006.

4. Bandali K, Niblett B, Yeung TPC, Gamble P. Beyond curriculum: embedding interprofessional collaboration into culture. Journal of Interprofessional Care. 2010;24:1-5.

5. Institute of Medicine. Crossing the quality chasm: a new health system for the 21st century. Washington, DC: National Academy Press; 2001.

6. Freeth D, Hammick M, Reeves S, Koppel I, Barr H. Effective interprofessional education, development, delivery and evaluation. Oxford: Blackwell Publishing; 2005.

7. Barker K, Bosco C, Oandasan I. Factors in implementing interprofessional education and collaborative practice initiatives: findings from key informant interviews. Journal of Interprofessional Care. 2005;19(Suppl 1):166-76. 
8. Oandasan I, Reeves S. Key elements for interprofessional education. Part 1: the learner, the educator and the learning context. Journal of Interprofessional Care. 2005;19(Suppl 1):21-38.

9. World Health Organisation (WHO). Framework for action on interprofessional education and collaborative practice. Geneva: WHO Health Professions Network Nursing and Midwifery Office; 2010.

10. Mackenzie A, Craik C, Tempest S, Cordingly K, Buckingham I, Hale S. Interprofessional learning in practice: the student experience. British Journal of Occupational Therapy. 2007;70:358-61.

11. Ponzer S, Hylin U, Kusoffsky A, Lauffs M, Lonka K, Mattiasson A, et al. Interprofessional training in the context of clinical practice: goals and students' perceptions on clinical education wards. Medical Education. 2004;38:727-736.

12. Reeves S, Zwarenstein M, Goldman J, Barr H, Freeth D, Hammick M, et al. Interprofessional education: effects on professional practice and health care outcomes. Cochrane Database Systematic Reviews. 2008;1:CD002213.

13. Thistlethwaite J. Interprofessional education: a review of context, learning and the research agenda. Medical Education. 2012;46:58-70.

14. Lapkin S, Levett-Jones T, Gilligan C. A systematic review of the effectiveness of interprofessional education in health professional programs. Nurse Education Today. 201. Epub ahead of print.

15. Pirrie A, Wilson V, Elsegood J, Hall J, Hamilton S, Harden R, et al. Evaluating multidisciplinary education in healthcare. Edinburgh: Scottish Council for Research in Education; 1998.

16. Steven A, Dickinson C, Pearson P. Practice-based interprofessional education: looking into the black box. Journal of Interprofessional Care. 2007;21:251-64.

17. Morison S, Boohan M, Jenkins J, Moutray M. Facilitating undergraduate interprofessional learning in healthcare: comparing classroom and clinical learning for nursing and medical students. Learning in Health and Social Care. 2003;2:92-104

18. Derbyshire JA, Machin AI. Learning to work collaboratively: nurses' views of their pre-registration interprofessional education and its impact on practice. Nurse Education and Practice. 2011;11:239-244.

19. Reeves S, Freeth D, McCrorie P, Perry D. 'It teaches you what to expect in future...': interprofessional learning on a training ward for medical, nursing, occupational therapy and physiotherapy students. Medical Education. 2002;36:337-44.

20. Wilhelmsson M, Pelling S, Ludvigsson J, Hammar J, Dahlgren L, Faresö T. Twenty years' experience of interprofessional education in Linköping groundbreaking and sustainable. Journal of Interprofessional Care. 2009;23:121-33

21. Bridges DR, Davidson RA, Odegard PS, Maki IV, Tomkowiak J. Interprofessional collaboration: three best practice models of interprofessional education. Medical Education Online. 2011;16:6035.

22. Chau J, Denomme J, Murray J, Cott CA. Interprofessional education in the acute-care setting: the clinical instructor's point of view. Physiotherapy Canada. 2010;63:65-75

23. Joseph S, Diack L, Garton F, Haxton J. Interprofessional education in practice. Clinical Teacher. 2012;9:27-31.

24. Galle J, Lingard L. A medical student's perspective of participation in an interprofessional education placement. Journal of Interprofessional Care. 2010;24:722-33.

25. Repper J, Breeze J. A review of the literature on user and carer involvement in the training and education of health professionals. Sheffield, UK: Sheffield University; 2004. [cited 29 February 2012]; Available from: http://www.shef.ac.uk/content/1/c6/01/34/62/Finalreport.pdf.

26. Braye S, Preston-Shoot M. Emerging from out of the shadows? Service user and carer involvement in systematic reviews. Evidence and Policy. 2005;1:173-93.

27. Rush B. Mental health service user involvement in nurse education: a catalyst for transformative learning. Journal of Mental Health. 2008;17:53142.

28. Coupland K, Davis E, Gregory K. Learning from life. Mental Health Care. 2001;4:166-9.

29. Hutchings D. Partnership in education: an example of client and educator collaboration. Journal of Continuing Education in Nursing. 1999;30:128-31.
30. Blicken C, Priyadharshini E. Patient narratives: the potential for 'patientcentred' interprofessional learning? Journal of Interprofessional Care. 2007;21:619-32

31. Furness PJ, Armitage HR, Pitt R. An evaluation of practice-based interprofessional education initiatives involving service users. Journal of Interprofessional Care. 2011;25:46-52.

32. Glasby J, Beresford P. Commentary and issues: who knows best? Evidence-based practice and service user contribution. Critical Social Policy. 2006;26:268-84

33. Allport GW. The nature of prejudice. Reading, MA: Addison-Wesley Publishing Company; 1954.

34. Hewstone M, Brown RJ. Contact is not enough: an intergroup perspective on the 'contact hypothesis'. In: Hewstone M, Brown RJ, editors. Contact and conflict in intergroup encounters. Oxford: Blackwell Publishing; 1986.

35. Carpenter J, Hewstone M. Shared learning for doctors and social workers; evaluation of a programme. British Journal of Social Work. 1996;26:239-57.

36. Barnes D, Carpenter J, Bailey D. Partnerships with service users in interprofessional education for community mental health: a case study. Journal of Interprofessional Care. 2000;14:189-200.

37. Hean S, Dickinson C. The contact hypothesis: an exploration of its further potential in interprofessional education. Journal of Interprofessional Care. 2005;19:480-91.

38. Armitage H, Connolly J, Pitt R. Developing sustainable models of interprofessional learning in practice: the TUILIP project. Nurse Education and Practice. 2008;8:276-82.

39. Kirkpatrick DL. Great ideas revisited. Training and Development Journal. 1996;50:54-9.

40. Barr H, Hammick M, Koppel I, Reeves S. Evaluating Interprofessional Education: two systematic reviews for health and social care. British Educational Research Journal. 1999;25:533-44.

41. Polit D, Hungler B. Nursing research: methods, appraisal and utilisation. 3rd ed. Philadephia, PA: Lippincott; 1993.

42. Jinks AM, Armitage H, Pitt. A qualitative evaluation of an interprofessional learning project. Learning in Health and Social Care. 2009;8:263-71.

43. Allport GW. The nature of prejudice. New York, NJ: Perseus Books; 1979.

44. Merton RK. Social theory and social structure. New York, NJ: Free Press; 1968.

45. Barnes D, Carpenter J, Dickinson C. Interprofessional education for community mental health: attitudes to community care and professional stereotypes. Social Work Education. 2000;19:565-83.

46. Reeves S, Freeth D, Glen S, Leiba T, Berridge EJ, Herzberg J. Delivering practice-based interprofessional education to community mental health teams: understanding some key lessons. Nurse Education and Practice. 2006;6:246-53.

47. Glen S, Reeves S. Developing interprofessional education in the preregistration curricula: mission impossible? Nurse Education and Practice. 2004;4:45-52.

48. Rees D, Johnson R. All together now? Staff views and experiences of a pre-qualifying interprofessional curriculum. Journal of Interprofessional Care. 2007;21:543-55

49. Rice K, Zwarenstein M, Gotlib Comm L, Kenaszchuk C, Russell A, Reeves S. An intervention to improve interprofessional collaboration and communication: a comparative qualitative study. Journal of Interprofessional Care. 2010;24:350-61.

50. Herber OR, Schnepp W, Rieger MA. Recruitment rates and reasons for community physicians' non-participation in an interdisciplinary intervention study on leg ulceration. British Medical Council Medical Research Methodology. 2009;9:61.

51. Harrison RA. Barriers and opportunities to developing research capacity in primary care trusts: the views of staff attached to a primary care trust. Primary Health Care Research and Development. 2005;6:185-9.

52. Smith R, Anderson L. Interprofessional learning: aspiration or achievement? Social Work Education. 2008;27:759-76.

53. Mattesich P, Murray-Close M, Monsey B. Collaboration: what makes it work? 2nd ed. St. Paul, MN: Amherst H Wilder Foundation; 2001. 